\title{
Quality of life related to clinical aspects in people with chronic wound
}

\author{
Qualidade de vida relacionada a aspectos clínicos em pessoas com ferida crônica \\ Calidad de vida relacionada con aspectos clínicos en personas con herida crónica
}

Maicon Henrique Lentsck ${ }^{1}$, Tatiane Baratieri ${ }^{1}$, Maria Regiane Trincaus ${ }^{1}$, Aline Padilha Mattei ${ }^{1}$, Carine Teles Sangaleti Miyahara ${ }^{1}$

How to cite this article:

Lentsck MH, Baratieri T, Trincaus MR, Mattei AP, Miyahara CTS. Quality of life related to clinical aspects in people with chronic wound. Rev Esc Enferm USP. 2018;52:e03384. DOI: http://dx.doi.org/10.1590/S1980-220X2017004003384

\author{
${ }^{1}$ Universidade Estadual do Centro- \\ -Oeste, Departamento de Enfermagem, \\ Guarapuava, PR, Brazil.
}

\begin{abstract}
Objective: To evaluate the quality of life of people with chronic wounds and to compare this index with clinical parameters. Method: A cross-sectional study conducted between July 2014 and February 2015, evaluating people with chronic wounds in outpatient care during a nursing consultation, in the city of Guarapuava, Paraná. Quality of life was assessed by the Quality of Life Index - wounds version. Data were analyzed using the Mann Whitney test and T-test. Results: 53 people participated. The mean quality of life score was $22.65 \pm 3.08$. The most significant scores in the analyzes were the family domain $(27.71 \pm 2.94)$ with the highest mean score, and the health domain $(18.91 \pm 4.58)$ had the lowest. Pain in walking $(\mathrm{p}=0.031)$ and using pain medication $(\mathrm{p}=0.002)$ presented a significant relation with overall score. There was a significant difference between the groups for the items pain at rest $(p=0.022)$, pain in moving $(p=0.006)$, using pain medication $(p<0.001)$ and presence of infection $(p=0.004)$, in the rest item $(p=0.015)$ in the socioeconomic domain, and type of wound $(p=0.05)$ and rest $(p=0.041)$ in the psychological domain. Conclusion: The overall Quality of Life Index and by domains was classified as good and very good, where the family domain was better evaluated to the detriment of the health domain due to the clinical parameter of pain.
\end{abstract}

DESCRIPTORS

Quality of Life; Wounds and Injuries; Pressure Ulcer; Ulcer; Nursing Care. 


\section{INTRODUCTION}

Quality of life (QoL) can be intensely altered by the presence of a chronic wound, since the chronification process of the lesion triggers a series of problems that affects the individual across several spheres - physical, psychological and/or social ${ }^{(1)}$. Chronic wounds are understood as those that do not heal within the expected time interval of up to 3 months, which remain stuck in one of the stages of the healing process ${ }^{(2)}$, and do not have a known prevalence rate in Brazil based on national studies. Furthermore, although this information is crucial to guide care actions aimed at this problem, there is in fact a shortage of studies on chronic wounds and their prevalence according to a literature review published in English ${ }^{(3)}$, corroborating that this lack of studies on the subject is not only restricted to Brazil. However, it is noted that these rates have been increasing due to the increase in the aging population and the expanding factors that favor its incidence, among which metabolic and vascular diseases are highlighted ${ }^{(4)}$.

In this scenario, local and regional studies which present data on the prevalence and etiology of chronic wounds help to outline this information. For example, a recent study with older adult patients attended in the primary care services in a state capital city in the Northeast region of Brazil found a prevalence of $8 \%$, with emphasis on pressure injuries (5\%) and venous wounds (2.9\%). The presence of chronic wound was associated with more advanced ages, lower education and a state of cognitive impairment ${ }^{(5)}$. The authors emphasize that chronic illness associated to factors that admittedly make them difficult to treat evidences the possible negative implications in the lives of the older adults evaluated.

In this context, quality of life (QoL) configures as a relevant evaluation parameter when a chronic condition is present. A study comparing the QoL of people with venous insufficiency (VI) with or without wounds in a mediumsized municipality in the state of São Paulo showed that the quality of life was lower among those with wounds due to impairment in functional capacity, physical health and their social insertion. The study found that $26.8 \%$ of participants had moderate to high impairment in this parameter ${ }^{(6)}$.

Investigations on the etiology, risk factors and treatment of chronic wounds resulted in evidence-based consensus and treatment guidelines ${ }^{(7)}$. However, overall management of the problem is still incipient, as people with chronic wounds have negative functional and psychological consequences, which generally result in poor $\mathrm{QoL}^{(8)}$. Even when promoting care that considers the best evidence, many wounds do not heal easily. Thus, QoL becomes an even more important element in the care plan in such situations.

It is known that there are innumerable factors which determine QoL for people with chronic wounds; these factors are related to physical functionality, psychosocial aspects and treatment, as well as financial commitment by both the individual, the health systems and society ${ }^{(9)}$. In addition, frequent complications that result in complex morbidities and the scarcity of care records are also systemic factors which interfere in the $\mathrm{QoL}^{(6)}$ of people with chronic wounds. However, the clinical pain parameter is the factor that most frequently influences the $\mathrm{QOL}^{(8)}$ of these people.

Thus, in addition to considering the influence of psychosocial aspects, there are also clinical variables which are included in evaluating a person with a wound during their treatment, and their influence on QoL must be investigated in aiming to improve the care provided to them ${ }^{(4,9)}$.

Studies indicate that clinical variables such as the presence of edema and comorbidities, the lesion extension and pain can also influence QoL $L^{(6,9)}$. Thus, it is necessary to know and to help patients with chronic wounds by considering such conditions, so that their demands are met and better results are achieved when providing treatment to them, giving them greater satisfaction. In this sense, the objective of this study was to evaluate the QoL of people with chronic wound(s), and to compare this index with clinical parameters.

\section{METHOD}

\section{Studi DESIGN}

This is a cross-sectional association study between clinical conditions and QoL index (QLI) of people with chronic wounds, attended at two specialized wound clinics connected to the Nursing Departments of two higher education institutions in the city of Guarapuava, Paraná, Brazil.

\section{Population}

The study was carried out from July 2014 to February 2015 , and the population was composed of all individuals attending the outpatient clinics, provided they met the following inclusion criteria: people with chronic wounds of any etiology, defined as active injury by a period greater than or equal to 3 months, and over 18 years old; and as exclusion criteria: people without cognitive conditions, evaluated according to the Mini Mental State Exam (MMSE). Fifty-three (53) people with chronic wounds were therefore eligible for the study.

\section{DATA COlLECTION}

Data were collected through two instruments: a questionnaire with questions about sociodemographic and clinical data, and the QoL assessment instrument specifically for the chronic wound condition. Three collection techniques were used: interview, brief clinical evaluation and of the wound location, and medical record analysis.

A pre-test of the instruments was conducted prior to data collection with five people who were also in ambulatory care, and who were not included in the study population. The pre-test aimed to improve the instrument for collecting sociodemographic and clinical information, as well as the collection techniques. The results of this pre-test resulted in changes in the way people were approached because of the difficulty they had in understanding some of the questions.

Data collection (including that of the pre-test) occurred during the nursing consultation by two previously-trained 
researchers and (two) nursing students in a reserved room, as provided by the outpatient clinics' administration in order to provide a calm and private environment.

The sociodemographic and clinical data collection instrument was elaborated by the researchers and approached the following variables: age, gender, marital status, family arrangement, education, occupation, housing condition, family income, comorbidities, smoking, insomnia and medication use. The following variables regarding the wound parameters were collected: wound etiology, number of wounds, dimensions, time of evolution, relapses, edema, inflammation and/or infection characteristics, and the presence of pain in the wound and/or limb. The Visual Analogue Scale (VAS) for pain ${ }^{(10)}$ was used for evaluating pain, and an evaluation of the clinical parameters followed the criteria established in the manual of conducts for neurotrophic and traumatic wounds ${ }^{(11)}$. Medical records were consulted in order to complement and confirm the information obtained in the interview and in the clinical evaluation.

QoL was evaluated through the Ferrans \& Powers Quality of Life Index (QLI) - wounds version ${ }^{(1)}$ questionnaire, composed of 35 items divided into four domains: Health and Functioning (HF), which contains 19 items; Socioeconomic (SE), five items; Psychological/Spiritual (PS), seven items; and Family (FA), four items. It is important to note that only 34 of the 35 items were computed in the final score, since items 16 (do you have children?) and 17 (the fact they do not have children?) of the Family domain were mutually exclusive. These domains were also divided into two sections: the first one related to experiences of satisfaction by the person in various aspects of life, and the second related to the importance that they attribute to these aspects.

The Ferrans \& Powers QLI - wound version questionnaire is multidimensional and was constructed and validated in Brazil by Yamada and Santos ${ }^{(1)}$, and presented an internal consistency of 0.90 for the complete instrument using the Cronbach's alpha coefficient, 0.88 for the HF domain, 0.65 for the SE, 0.81 for the PS domain, and 0.55 for the FA.

For constructing the QoL index, the 34 items in the satisfaction section were weighted by their corresponding items in the importance section. The response for each item of satisfaction was measured on a Likert scale $(1,2,3,4,5$ and 6), ranging from "very unsatisfied/no importance" to "very satisfied/important". Next, 3.5 points were subtracted for each response with a value attributed to satisfaction, thus obtaining new values $(-2.5,-1.5,-0.5,0.5,1.5,2.5)$. These new satisfaction values were multiplied by the absolute values corresponding to each response in the importance section. Fifteen (15) points are then added to each value to reach the final score in order to obtain a positive value for each item, which varies from 0 to 30 , and the highest values indicate higher QoL. The total score is calculated by summing the weighted values of all items answered and dividing the result by the total response. The same procedure was adopted to obtain the scores for each domain ${ }^{(1)}$.
The instrument does not present any cut-off point, however, the Yamada and Santos ${ }^{(1)}$ categorization was implemented with the following scale: 0 to 5 (very poor QoL), 6 to 11 (poor QoL), 12 to 17 (Regular QoL), 18 to 23 (good QoL) and 24 to 30 (very good QoL).

\section{DATA ANALYSIS AND PROCESSING}

The data were organized in the Microsoft Office Excel 2007 program, and statistical analyzes were performed using the SPSS program, version 20.0 (SPSS Inc., Chicago, IL, USA). Regarding the database, it should be pointed out that there was no missing data. The data were initially evaluated descriptively by means, standard deviations and frequencies. The clinical variables were dichotomized, and their mean values were compared according to the values of general and domain QoL scores. The differences between the means were analyzed using the t-test for the independent samples presenting normality, or the Mann Whitney $U$ test for the non-parametric data. $\mathrm{P}<0.05$ was considered as the level of statistical significance. Cronbach's alpha was used to evaluate the internal consistency of the questionnaire in the study population. The results were organized and presented in tables and discussed in view of the scientific literature on the subject.

\section{ETHICAL ASPECTS}

The study was approved by the Ethics Committee in Research with human beings of the Universidade Estadual do Centro-Oeste - UNICENTRO (622.733/2014), in accordance with Resolution no. 466 of December 12th, 2012, of the National Health Council, and written informed consent was obtained from all participants.

\section{RESULTS}

The sociodemographic characterization of the participants showed a majority $(69.8 \%)$ of males, with a mean age of $58.4 \pm 12.7(18.0-79.0)$ years, $60.4 \%$ were married, $64.2 \%$ had one to three children, $86.8 \%$ were Catholics, $77.2 \%$ were educated, and $71.7 \%$ of these only until Elementary School. Regarding occupation, $71.7 \%$ did not work, while $83 \%$ had a family income of up to two minimum wages and had their own house with up to three residents at home.

According to Table 1, the majority of participants (90.6\%) were living with another chronic disease, with hypertension being the most prevalent (71.7\%). Pain at rest and during movement was not reported by more than half of the respondents; however, $56.6 \%$ used continuous analgesics. Daytime rest was performed by $69.8 \%$ of the participants, $56.6 \%$ reported their sleep routine being longer than 7 hours a day, $73.4 \%$ did not present insomnia, and $86.8 \%$ were not smokers.

There was a predominance of lesions with venous etiology $(64.2 \%)$, with a wound (54.7\%) and lesion recurrence after treatment in $56.6 \%$ of the interviewees. The time of the current wound was less than 5 years in $66.0 \%$ of the cases, and the lesion size was less than $4 \mathrm{~cm}^{2}$ (24.2\%), without edema (88.7\%), according to Table 2. 
Table 1 - Distribution of the interviewees according to clinical characteristics - Guarapuava, PR, Brazil, 2015.

\begin{tabular}{lcccc}
\hline \multirow{2}{*}{ Clinical characteristics } & \multicolumn{2}{c}{ Yes } & \multicolumn{2}{c}{ No } \\
\cline { 2 - 5 } & $\mathbf{n}$ & $\%$ & $\mathbf{n}$ & $\%$ \\
\hline Chronic disease & 48 & 90.6 & 5 & 9.4 \\
Leprosy & 8 & 15.1 & 45 & 84.9 \\
Diabetes mellitus & 18 & 34.0 & 35 & 66.0 \\
Systemic arterial hypertension & 38 & 71.7 & 15 & 28.3 \\
Chronic venous insufficiency & 30 & 56.6 & 23 & 43.4 \\
Resting pain & 24 & 45.3 & 29 & 54.7 \\
Walking pain & 26 & 49.1 & 27 & 50.9 \\
Pain medication & 30 & 56.6 & 23 & 43.4 \\
Resting & 37 & 69.8 & 16 & 30.2 \\
Sleep time $\leq 7$ hours & 23 & 43.4 & 30 & 56.6 \\
Insomnia & 14 & 26.4 & 39 & 73.4 \\
Smoking & 7 & 13.2 & 46 & 86.8 \\
\hline Note:
\end{tabular}

Note: $\mathrm{n}=53$.

Table 2 - Distribution of the interviewees according to the clinical characteristics of the chronic wounds - Guarapuava, PR, Brazil, 2015.

\begin{tabular}{|c|c|c|}
\hline Clinical characteristics & $n=53$ & $\%(100)$ \\
\hline \multicolumn{3}{|l|}{ Wound etiology } \\
\hline Venous & 34 & 64.2 \\
\hline Neuropathic & 8 & 15.1 \\
\hline Pressure & 4 & 7.5 \\
\hline Traumatic/amputation & 3 & 5.7 \\
\hline Mixed & 3 & 5.7 \\
\hline Arterial & 1 & 1.9 \\
\hline \multicolumn{3}{|l|}{ Number of wounds } \\
\hline 1 & 29 & 54.7 \\
\hline 2 or more & 24 & 45.3 \\
\hline \multicolumn{3}{|l|}{ Wound recurrence } \\
\hline Yes & 30 & 56.6 \\
\hline No & 23 & 43.4 \\
\hline \multicolumn{3}{|l|}{ Current wound time } \\
\hline$\leq 5$ years & 35 & 66.0 \\
\hline$>5$ years & 18 & 34.0 \\
\hline \multicolumn{3}{|l|}{ Size $\left(\mathrm{cm}^{2}\right)$} \\
\hline$\leq 4$ & 13 & 24.5 \\
\hline 4.1 to 16 & 12 & 22.6 \\
\hline 16.1 to 36.0 & 10 & 18.9 \\
\hline 36.1 to 80.0 & 10 & 18.9 \\
\hline \multicolumn{3}{|l|}{ Edema } \\
\hline Yes & 6 & 11.3 \\
\hline No & 47 & 88.7 \\
\hline
\end{tabular}

Note: $\mathrm{n}=53$.

Table 3 presents the general QLI and by domains, with the general one being $22.6 \pm 3.2$. The questionnaire presented high scores for most domains, especially the family dimension $(27.7 \pm 2.9)$. The health dimension presented the lowest score among all $(18.9 \pm 4.6)$. The Cronbach's alpha for the QLI - wounds version was 0.80 , which suggests adequate internal consistency and homogeneity, thus confirming suitability of the instrument for use of that specific population. Similar to the validation study of the QLI questionnaire, the Cronbach's alpha values in the family and socioeconomic domains were smaller when compared to the other domains.

Table 3 - Distribution of quality of life among people with chronic wounds according to domains - Guarapuava, PR, Brazil, 2015.

\begin{tabular}{lcccccc}
\hline \multicolumn{1}{c}{ Domains } & Mean & SD & Min.-Max. & Median & Cl 95\% & $\begin{array}{c}\text { Cronbach's } \\
\text { alpha }\end{array}$ \\
\hline Health & 18.9 & 4.6 & $8.9-29.0$ & 17.8 & $17.8-20.1$ & 0.80 \\
Socioeconomic & 26.7 & 3.5 & $16.3-30.0$ & 27.6 & $25.6-27.0$ & 0.45 \\
Psychological & 26.1 & 3.4 & $13.6-30.0$ & 26.6 & $25.2-27.0$ & 0.69 \\
Family & 27.7 & 2.9 & $19.0-30.0$ & 26.6 & $26.9-28.5$ & 0.24 \\
General QL** & 22.6 & 3.2 & $17.2-29.9$ & 21.9 & $21.8-23.5$ & 0.80 \\
\hline
\end{tabular}

*Quality of Life Index.

Note: $\mathrm{n}=53$.

Regarding the QoL categorization, Table 4 shows that most people had good QoL (60.3\%), and no participant had a general score that was categorized as very poor or poor.

Table 4 - Distribution of the quality of life classification of people with chronic wounds according to categories proposed for QoL* - Guarapuava, PR, Brazil, 2015.

\begin{tabular}{lcc}
\hline \multicolumn{1}{c}{ Category } & $\mathbf{n = 5 3}$ & \% (100) \\
\hline Average (12 to 17$)$ & 3 & 5.7 \\
Good (18 to 23$)$ & 32 & 60.3 \\
Very good (24 to 30) & 18 & 34.0 \\
\hline
\end{tabular}

*QoL: Quality of Life.

Note: $\mathrm{n}=53$.

According to the proposed objective, overall QLI scores and domains were examined according to groups of clinical variables and life habits (Table 5). Of the analyzed variables for general QoL, only the pain in movement groups ( $p=$ $0.027)$ and use of medication for pain $(p=0.002)$ were different from each other, with higher QoL for individuals who did not feel pain and did not use medication.

Comparison of scores by domains revealed that mean QoL scores in the health dimension were significantly different in the groups with pain at rest $(p=0.024)$, pain in movement $(p=0.004)$ and use of pain medication $(p<0.001)$. These scores were lower than among groups who did not have/present such variables.

In the socioeconomic domain, only the resting variable presented significant differences between the groups, with a higher QoL for those who rested daily $(\mathrm{p}=0.030)$. There was no significant difference between the groups in the other domains, as indicated in Table 5.

In the present study, the relationship between general QLI and domains with associated pathologies (leprosy, diabetes mellitus, arterial hypertension and chronic venous insufficiency) was also tested, and there were no significant differences between the groups; therefore, interference of these injuries in the QoL of the studied population was not verified. 
Table 5 - Distribution of the relationship between clinical variables and life habits and quality of life in people with chronic wounds Guarapuava, PR, Brazil, 2015.

\begin{tabular}{|c|c|c|c|c|c|}
\hline \multirow{2}{*}{ Variables } & Overall QLI* & Health & Socioeconomic & Psychological & Family \\
\hline & Mean \pm SD & Mean \pm SD & Mean \pm SD & Mean \pm SD & Mean \pm SD \\
\hline \multicolumn{6}{|c|}{ Chronic disease } \\
\hline Yes & $22.8 \pm 2.9$ & $19.1 \pm 4.4$ & $26.8 \pm 3.0$ & $26.2 \pm 3.4$ & $27.7 \pm 3.0$ \\
\hline No & $21.2 \pm 4.2$ & $16.6 \pm 5.8$ & $24.3 \pm 7.1$ & $25.7 \pm 3.5$ & $28.1 \pm 2.3$ \\
\hline \multicolumn{6}{|c|}{ Number of Wounds } \\
\hline 1 wound & $22.9 \pm 3.5$ & $19.4 \pm 5.3$ & $26.6 \pm 2.8$ & $25.9 \pm 4.1$ & $27.8 \pm 2.9$ \\
\hline 2 or more & $22.3 \pm 2.5$ & $18.3 \pm 3.6$ & $26.5 \pm 4.3$ & $26.4 \pm 2.3$ & $27.6 \pm 3.0$ \\
\hline \multicolumn{6}{|l|}{ Recurrences } \\
\hline Yes & $22.4 \pm 3.4$ & $18.5 \pm 4.4$ & $26.3 \pm 4.0$ & $26.5 \pm 2.2$ & $27.1 \pm 3.5$ \\
\hline No & $22.9 \pm 2.7$ & $19.4 \pm 4.9$ & $26.8 \pm 2.8$ & $25.9 \pm 4.1$ & $28.2 \pm 2.3$ \\
\hline \multicolumn{6}{|c|}{ Current wound time } \\
\hline$<=5$ years & $22.6 \pm 2.9$ & $19.8 \pm 4.2$ & $26.0 \pm 3.8$ & $26,0 \pm 3,6$ & $27.4 \pm 3.2$ \\
\hline$>5$ years & $22.7 \pm 3.4$ & $18.4 \pm 5.2$ & $27.5 \pm 2.7$ & $26.4 \pm 3.0$ & $28.3 \pm 2.4$ \\
\hline \multicolumn{6}{|l|}{ Wound type } \\
\hline Venous & $22.9 \pm 3.0$ & $19.2 \pm 4.5$ & $26.8 \pm 2.9$ & $26.6 \pm 3.3$ & $27.9 \pm 3.9$ \\
\hline Others & $22.0 \pm 3.2$ & $18.4 \pm 4.7$ & $26.0 \pm 4.4$ & $25.2 \pm 3.4$ & $27.4 \pm 3.0$ \\
\hline \multicolumn{6}{|l|}{ Wound size } \\
\hline 0 to $16 \mathrm{~cm}^{2}$ & $22.4 \pm 3.3$ & $18.7 \pm 4.9$ & $26.5 \pm 3.3$ & $25.6 \pm 3.9$ & $27.6 \pm 3.3$ \\
\hline$+16 \mathrm{~cm}^{2}$ & $22.9 \pm 2.8$ & $19.2 \pm 4.2$ & $26.6 \pm 3.8$ & $26.8 \pm 2.4$ & $27.9 \pm 2.4$ \\
\hline \multicolumn{6}{|l|}{ Resting pain } \\
\hline Yes & $21.9 \pm 2.7$ & $17.3^{* *} \pm 4.2$ & $26.3 \pm 3.9$ & $25.9 \pm 3.4$ & $27.5 \pm 3.3$ \\
\hline No & $23.2 \pm 3.3$ & $20.2^{* *} \pm 4.5$ & $26.9 \pm 3.0$ & $26.4 \pm 3.4$ & $28.0 \pm 2.5$ \\
\hline \multicolumn{6}{|l|}{ Walking pain } \\
\hline Yes & $21.7^{* *} \pm 2.8$ & $17.2 * \pm 4.0$ & $26.8 \pm 2.9$ & $25.9 \pm 3.9$ & $28.0 \pm 2.6$ \\
\hline No & $23.5^{* *} \pm 3.1$ & $20.5^{*} \pm 4.5$ & $26.4 \pm 4.1$ & $26.3 \pm 2.8$ & $27.4 \pm 3.3$ \\
\hline \multicolumn{6}{|c|}{ Medication use for pain } \\
\hline Yes & $21.5^{* *} \pm 2.7$ & $16.9 * * \pm 4.1$ & $26.7 \pm 4.1$ & $25.8 \pm 3.8$ & $27.9 \pm 2.8$ \\
\hline No & $24.1 * * \pm 2.9$ & $21.5^{* *} \pm 3.9$ & $26.4 \pm 3.1$ & $26.5 \pm 2.8$ & $27.4 \pm 3.2$ \\
\hline \multicolumn{6}{|l|}{ Edema } \\
\hline Yes & $22.8 \pm 3.2$ & $18.9 \pm 4.9$ & $27.2 \pm 3.4$ & $26.0 \pm 2.3$ & $29.3 \pm 1.6$ \\
\hline No & $22.6 \pm 3.1$ & $18.9 \pm 4.6$ & $26.5 \pm 3.6$ & $26.1 \pm 3.5$ & $27.5 \pm 3.0$ \\
\hline \multicolumn{6}{|l|}{ Infection } \\
\hline Yes & $20.2 \pm 2.3$ & $16.7 \pm 0.4$ & $22.5 \pm 8.8$ & $23.5 \pm 3.1$ & $25.2 \pm 1.2$ \\
\hline No & $22.7 \pm 3.1$ & $19.0 \pm 4.6$ & $26.7 \pm 3.3$ & $26.2 \pm 3.4$ & $28.0 \pm 2.9$ \\
\hline \multicolumn{6}{|l|}{ Rest } \\
\hline Yes & $22.9 \pm 3.3$ & $19.0 \pm 5.0$ & $27.3^{* * *} \pm 3.0$ & $26.4 \pm 3.7$ & $28.0 \pm 2.6$ \\
\hline No & $22.0 \pm 2.5$ & $18.7 \pm 3.6$ & $24.8^{* * *} \pm 4.1$ & $25.5 \pm 2.6$ & $27.0 \pm 3.5$ \\
\hline
\end{tabular}

* Quality of Life Index;

** Significant differences $(\mathrm{p}<0.05)$ of the means between the indicated groups;

*** Significant differences $(\mathrm{p}<0.01)$ of the means between the indicated groups;

***** Student's T-Test and Mann Whitney test.

Note: $\mathrm{n}=53$.

\section{DISCUSSION}

QoL has been frequently used in health research, and its concept has been developed in the context of several user groups of health services having a wide range of injuries ${ }^{(12)}$. The change in the morbidity and mortality profile, the increase in chronic conditions, and the disabilities related to them, in addition to making changes in the health system, require new positioning by professionals in relation to caregiving actions, with a lesser curative focus on specific complaints and greater attention to health needs that impact the improvement of QoL of people with chronic conditions ${ }^{(12)}$. 
Chronic wounds are a growing problem in the public health field, since their complications impact life, social and family relations of the individual affected by them. The practical applicability of studies on the QoL of a person with a chronic wound is able to provide subsidies for elaborating strategies that improve the relations between professionals and users, for preparing professionals and for the preventive approach ${ }^{(13)}$.

In Brazil, there are still few studies on the QoL of people with chronic wounds, and the existing ones evaluate this index with non-specific instruments, and they are not adapted or validated for the Brazilian culture. The QLI wound version is specifically aimed at this population, and its items reflect the common and relevant factors to those affected by chronic wounds; thus, it is able to more accurately identify important QoL dimensions ${ }^{(1)}$.

In this study, even though there was no control group, the general QLI scores and by domains was high. A similar result was found in a study of the construction and validation of the QLI - wounds in Brazil ${ }^{(1)}$, in a study of people with vasculogenic ulcers attended at a university hospital in the South of $\mathrm{Brazi}^{(14)}$, and in a recent study with people presenting wounds who were attended in basic health units in two cities in southeast $\mathrm{Brazi}^{(10)}$. Similar to the aforementioned studies ${ }^{(1,10)}$, the family domain in the analysis of QoL by domains in this study was better evaluated to the detriment of the health domain.

The QLI classification obtained in this study may be a reflection of the greater resilience of wounded patients in relation to this problem as justified by the time of the active wound, and in this case by accepting their complications and consequences in daily activities. Resilience is a state that has not yet been explored in the context of chronic wounds, but it is pointed out as an important factor in facing pathological chronic conditions and improving perception about $\mathrm{QoL}^{(15)}$. In addition, it should not be disregarded that full access to the treatment provided in outpatient care clinics can have an influence on the results.

In turn, the highest QLI associated with the family domain demonstrates the importance of family participation in treating people with wounds due to the possibility of sharing the problem, so that it is not perceived as something individual, but rather familiar ${ }^{(10)}$.

Factors of pain level, disposition to treatment, presence of associated diseases and other comorbidities, as well as certain habits and lifestyles are directly related to treatment success of chronic wounds. In this study, pain (evaluated in several items) was a clinical determinant for worse QLI evaluation in the health domain in relation to the other domains. For a person with a chronic wound, having health is having freedom and independence to develop their activities, and the fact that the pain related to the wound changed their daily life is reason to perceive that their health is impaired ${ }^{(14)}$.

Pain is, in fact, a factor that stands out because it affects health and impairs $\operatorname{QoL}^{(7-8)}$ in the most diverse pathological contexts. Its measurement is highly valued in the context of malignant neoplasms, but sometimes neglected in other conditions in which it is mistakenly admitted that there is constant living with pain ${ }^{(16)}$.
Thus, in addition to being a constant complaint ${ }^{(17)}$, pain is often the most important factor affecting people with wounds. In a study that evaluated the health-related QoL and its predictive factors for people with chronic wounds in specialized outpatient treatment, it was pointed out that the increase in pain was associated with a decrease in overall $\mathrm{QLI}^{(7-8)}$. A systematic qualitative research review of the experiences of people living with venous leg ulcers identified that pain related to wound and treatment, as well as odor and exudate characteristics, appeared to have direct negative effects on their QoL perception, with additional and cumulative effects on sleep, mobility and mood ${ }^{(18)}$.

These data show that the different evaluation domains of QoL differently influence people with chronic wounds. Thus, an evaluation of this index should serve as a subsidy for clinical practice in the most varied health care scenarios. This is what was observed in a study that evaluated $\mathrm{QoL}^{(19)}$ in people with venous ulcer before and after topical sevoflurane application. The results demonstrated an improvement in QoL and functional capacity after the intervention, especially for providing quick and lasting reduction in pain. Other studies have demonstrated that factors related to the health domain, including vitality ${ }^{(20)}$, functional capacity ${ }^{(21)}$, fatigue, sleep disorder, depression, nutritional changes, odor, pruritus, exudation ${ }^{(20)}$, and pain ${ }^{(7,18)}$ frequently impair the QoL of people with a wound, particularly the clinical pain parameter.

Understanding the pain mechanisms related to the complex chronification of an injury can improve the QoL of a person with a wound because it qualifies care. Therefore, it should be an important part of the clinical evaluation during the provided care. In the present study, the group of individuals who used analgesics also presented lower QLI in the health domain, which may indicate that the treatment with analgesia was not effective, or that the pain was being underestimated.

Pain is still an important factor that influences physical activity and the daily lives of people with chronic wounds, as it limits an individual's mobility. In a study carried out in the Southeast region of Brazil in hospitalization units and outpatient care ${ }^{(14)}$, people with chronic wounds had worse QoL because of a lack of energy and willingness to perform daily activities, but having a chronic wound did not affect their self-esteem. It should be noted that recent research has identified that physical inactivity was one of the risk factors for venous ulceration, and physical exercise, in this case, attenuated this risk ${ }^{(8)}$.

The influence of pain on limiting physical activity and in causing sleep and rest problems, mood alteration and depression have already been described in the literature ${ }^{(22)}$, revealing impairment in interpersonal relationships with family and friends, loss of sleep, exhaustion and worry. Such implications of pain in the lives of people living with it may explain the lower QoL assessed in the health domain found in this study.

Chronic wounds are commonly associated with other pathological conditions such as arterial hypertension, venous and arterial vascular insufficiency, and diabetes. These diseases constitute etiological or aggravating factors of the wounds, so they may interfere with $\mathrm{QoL}^{(23)}$. No differences were observed in the QoL levels between the groups when 
other conditions and aggravations were analyzed in the present study. However, the associations between chronic uncontrolled conditions and the presence of pain cannot be disregarded. If QoL is influenced by pain, all possible triggers or aggravating factors of pain should be investigated.

It should also be noted that the differentiated etiology of the lesions in this study was not a factor that altered the QoL among the interviewees. It is known that venous wounds account for about $80 \%$ of chronic wounds, and the associated symptoms and treatments have an effect on QoL related to the health domain ${ }^{(18)}$. The results of the present study corroborate the data showing greater prevalence of the venous etiology, however the QLI of the people with the referred complaint did not differ in relation to the people with other types of wounds.

The presence of a chronic wound can cause depression, shame $^{(23)}$, social isolation ${ }^{(24-25)}$, anxiety, and low self-esteem ${ }^{(25)}$, causing daily changes, going through pain and physical discomfort, as well as causing social, family and psychological conflicts $^{(26)}$. However, family domain scores were the most well evaluated in this study, and determinants of overall QoL classification. Family support has become a more relevant factor in determining the degree of life satisfaction by a person with a wound, and this positive aspect must be addressed in care so that encouraging family participation in care is maintained. The importance of family support on QoL levels has already been demonstrated in several studies, for example, among people with cancer ${ }^{(27)}$.

In the QLI wound version, the social domain encompasses items that seek to grasp the way in which people deal with the problems caused by the wound, how these problems affect their social life, and include information about restrictions on activities and social contact with friends and relatives. There was only a relation with resting for this domain, indicating better $\mathrm{QLL}$ for those who performed it more.

Limb elevation is one of the most recommended resting methods for people with chronic wounds of venous etiology, or who have vascular edema; it is a proven action in reducing pain, edema and improving local circulation ${ }^{(23)}$. In addition, this action is important for those individuals who are unable to adhere to a regimen of compression therapy ${ }^{(28)}$. The ability to perform rest can also reflect adherence to self-care measures, as well as the social and family support that the person with the wound has in order to be able to take care of themselves day-to-day.

Thus, based on the results, it is possible to suggest that implementing instruments to assess the QoL of people with chronic wounds can help to develop an individualized care plan for each person, thus improving the health care that is provided for them.

Although wound treatment occurs in several clinical contexts and by several health professionals, it is important to emphasize that nurses are the main professional who work in providing care for wounded people, and should use guidelines and instruments to improve their clinical practice by incorporating evidence into their daily practice in treating people with wounds. Evidence-based care suggests that the use of a multidisciplinary approach and specialized care in exclusive outpatient clinics to care for people with chronic wounds improves outcomes, and that a specialized nurse who is a manager of chronic wound care will be able to employ primary and secondary care prevention strategies ${ }^{(29)}$.

The limitations in the results of this study refer to its cross-sectional design, which does not enable establishing cause and effect relationships, but is able to point out important associations. Another aspect is that the high QLIs found herein may have been directly influenced by the scenario of this study, meaning there was greater expectation regarding higher quality treatment from the moment these people started to receive specialized care, and consequently a significant improvement in the pain process and other aspects that influence QoL.

Regarding the study limitations, the family and socioeconomic domains presented low reliability according to the Cronbach alpha value. However, low Cronbach alpha values do not necessarily reflect low internal consistency, since this coefficient can be influenced by the number of items of the evaluated domain and the number of respondents ${ }^{(30)}$. Thus, considering that there was no missing data in the present study, and the questionnaire was applied to its target population, including the inclusion criteria highlighted in the QLI validation study, the low internal consistency values may be related to the number of items in the family and socioeconomic domains, namely four and five, respectively. This characteristic determines little variability in the participants' answers on the items of these dimensions; a fact that was also identified in the questionnaire's validation research, resulting in lower alpha values ${ }^{(1)}$.

In spite of the limiting factors, the importance of the instrument used in this study is emphasized, as it has been validated for the Brazilian culture and is able to meet the needs of health services that provide comprehensive care; and also the verified difference in QoL can contribute to a search of prevention strategies and to minimize aggravations to different groups of people with chronic wounds.

\section{CONCLUSION}

Although chronic wounds have a negative impact on people's lives, overall QLI and domains were found to be high in the study population. The best evaluated domain was the family, and the worst was health. Pain was the clinical parameter that most negatively impacts QoL, especially when compared to the groups that use analgesic medication and continue to endure pain both at rest and when moving. Recognizing these factors can positively influence organizing care to be provided in a comprehensive manner, as well as being very important for the individual.

As a recommendation and given the importance of the studied problem, it is considered necessary to create and improve comprehensive care environments in a context centered on the person and their family along with $\mathrm{QoL}$ identification, which is admittedly a supplementary tool for care planning. It is suggested that new studies be performed which address the importance of the family in providing care for people with chronic wounds, and which explore the health and clinical conditions raised in this study as QoL exponents in the studied population. Additionally, follow-up studies are critical in order to identify cause and effect of clinical conditions on the QoL of people with chronic wounds. 


\section{RESUMO}

Objetivo: Avaliar a qualidade de vida de pessoas com ferida crônica e comparar esse índice com parâmetros clínicos. Método: Estudo transversal, realizado entre julho de 2014 e fevereiro de 2015, com pessoas portadoras de ferida crônica, em atendimento ambulatorial, durante consulta de enfermagem, no município de Guarapuava, Paraná. A qualidade de vida foi avaliada pelo Índice de Qualidade de Vida - versão feridas. Os dados foram analisados por meio dos testes t e de Mann Whitney. Resultados: Participaram 53 pessoas. O escore médio de qualidade de vida foi de $22,65 \pm 3,08$. Nas análises, destacaram-se os domínios família $(27,71 \pm 2,94)$, com o maior escore médio, e saúde $(18,91 \pm 4,58)$, com o menor. Dor ao deambular $(\mathrm{p}=0,031)$ e uso de medicamento para dor $(\mathrm{p}=0,002)$ apresentaram relação significativa com escore geral. Constatou-se diferença significativa entre os grupos nos itens dor em repouso ( $p=0,022)$, dor ao deambular $(\mathrm{p}=0,006)$, uso de medicação para dor $(\mathrm{p}<0,001)$ e presença de infecção $(\mathrm{p}=0,004)$, e no item repouso ( $\mathrm{p}=0,015)$ no socioeconômico, e tipo de ferida $(\mathrm{p}=0,05)$ e repouso $(\mathrm{p}=0,041)$ no psicológico. Conclusão: O Indice de Qualidade de Vida geral e por domínios foi classificado como bom e muito bom, o domínio família foi mais bem avaliado em detrimento do domínio saúde, devido ao parâmetro clínico da dor.

\section{DESCRITORES}

Qualidade de Vida; Ferimentos e Lesões; Lesão por Pressão; Cuidados de Enfermagem.

\section{RESUMEN}

Objetivo: Evaluar la calidad de vida de personas con herida crónica y comparar ese índice con parámetros clínicos Método: Estudio transversal, realizado entre julio de 2014 y febrero de 2015, con personas portadoras de herida crónica, en atención ambulatoria, durante consulta de enfermería, en el municipio de Guarapuava, Paraná. La calidad de vida fue valorada por el Índice de Calidad de Vida versión heridas. Los datos fueron analizados mediante las pruebas t y de Mann Whitney. Resultados: Participaron 53 personas. El score medio de calidad de vida fue de 22,65 $\pm 3,08$. En los análisis, se destacaron los dominios familia $(27,71 \pm 2,94)$, con el mayor score medio, y salud $(18,91 \pm 4,58)$, con el menor. Dolor al deambular $(\mathrm{p}=0,031)$ y uso de fármaco para dolor $(\mathrm{p}=0,002)$ presentaron relación significativa con el score general. Se constató diferencia significativa entre los grupos en los puntos dolor en reposo ( $p=0,022)$, dolor al deambular $(p=0,006)$, uso de fármaco para dolor $(p<0,001)$ y presencia de infección $(p=0,004)$ y en el punto reposo $(p=0,015)$ en el socioeconómico, y tipo de herida $(\mathrm{p}=0,05)$ y reposo $(\mathrm{p}=0,041)$ en el psicológico. Conclusión: El Índice de Calidad de Vida general y por dominios fue clasificado como bueno y muy bueno, el dominio familia fue más bien evaluado en detrimento del dominio salud, en virtud del parámetro clínico del dolor.

\section{DESCRIPTORES}

Calidad de Vida; Heridas e Lesiones: Úlcera por Presión; Atención de Enfermería.

\section{REFERENCES}

1. Yamada BFA, Santos VLCG. Development and validation of Ferrans \& Powers Quality of Life Index: wound version. Rev Esc Enferm USP [Internet]. 2009 [cited 2016 July 16];43(n.spe):1103-11. Available from: http://www.scielo.br/pdf/reeusp/v43nspe/en_a15v43ns.pdf

2. Nunan R, Harding KG, Martin P. Clinical challenges of chronic wounds: searching for an optimal animal model to recapitulate their complexity. Dis Model Mech. 2014;7(11):1205-13.

3. Graves N, Zheng H. The prevalence and incidence of chronic wounds: a literature review. Wound Pract Res. 2014;22(1):4-19.

4. Wachholz PA, Masuda PY, Nascimento DC, Taira CMH, Cleto NG. Quality of life profile and correlated factors in chronic leg ulcer patients in the mid-west of São Paulo State, Brazil. An Bras Dermatol. 2014;89(1):73-81.

5. Vieira CPB, Furtado AS, Almeida PCD, Luz MHBA, Pereira AFM. Prevalência e caracterização de feridas crônicas em idosos assistidos na atenção básica. Rev Baiana Enferm. 2017;31(3):e17397.

6. Dias TYAF, Costa IKF, Melo MDM, Torres SMSGO, Maia EMC, Torres GV. Quality of life assessment of patients with and without venous ulcer. Rev Latino Am Enfermagem [Internet]. 2014 [cited 2016 Aug 22]; 22 (4): 576-81. Available from: http://www.scielo.br/pdf/rlae/ v22n4/0104-1169-rlae-22-04-00576.pdf

7. O'Donnell Jr. TF, Passman MA, Marston WA, Ennis WJ, Dalsing M, Kistner R, et al. Management of venous leg ulcers: clinical practice guidelines of the Society for Vascular Surgery® and the American Venous Forum. J Vasc Surg. 2014;60(2):3S-59S.

8. Santos VLCG, Oliveira AS, Amaral AFS, Nishi ET, Junqueira JB, Kim SHP. Quality of life in patients with chronic wounds: magnitude of changes and predictive factors. Rev Esc Enferm USP. 2017;51:e03250. DOI: http://dx.doi.org/10.1590/s1980-220x2016049603250

9. Santos KFR, Silva PR, Ferreira VT, Domingues EAR, Simões IRA, Lima RS, et al. Quality of life of people with chronic ulcers. J Vasc Nurs. 2016;34(4):131-6.

10. Aksoy H, Yücel B, Aksoy U, Acmaz G, Aydin T, Babayigit A. The relationship between expectation, experience and perception of labour pain: an observational study. Springerplus. 2016;5(1):1766.

11. Brasil. Ministério da Saúde; Secretaria de Políticas de Saúde, Departamento de Atenção Básica. Manual de condutas para feridas neurotróficas e traumáticas. Brasília; 2002.

12. World Health Organization. Quality of Life assessment (WHOQOL): position paper from the World Health Organization. Soc Sci Med. 1995;41(10):1403-9.

13. Souza DMST, Borges FR, Juliano Y, Veiga DF, Ferreira LM. Quality of life and self-esteem of patients with chronic ulcers. Acta Paul Enferm. 2013;26(3):283-8.

14. Sella BT, Souza MV, Martins T, Amante LN. Qualidade de vida de pessoas com úlceras vasculogênicas segundo Ferrans e Powers: versão feridas. J Health Sci. 2015;17(3):160-4.

15. Ousey K, and Edward KL. Exploring resilience when living with a wound: an integrative literature review. Healthcare (Basel). 2014;2(3):346-55. 
16. Santoro D, Satta E, Messina S, Costantino G, Savica V, Bellinghieri G. Pain in end-stage renal disease: a frequent and neglected clinical problem. Clin Nephrol. 2013;79(1):S2-11.

17. Hopman WM, Buchanan M, VanDerKerkhof EG, Harrison MB. Pain and health-related quality of life in people with chronic leg ulcers. Chronic Dis Inj Can. 2013;33(3):167-74.

18. Phillips P1, Lumley E, Duncan R, Aber A, Woods HB, Jones GL, Michaels J. A systematic review of qualitative research into people's experiences of living with venous leg ulcers. J Adv Nurs. 2018;74(3):550-63

19. Imbernon-Moya A, Ortiz-de Frutos FJ, Sanjuan-Alvarez M, Portero-Sanchez I, Merinero-Palomares R, Alcazar V. Pain, quality of life, and functional capacity with topical sevoflurane application for chronic venous ulcers: a retrospective clinical study. EJVES Short Rep. 2017;36:9-12.

20. Souza EM, Yoshida WB, Melo VA, Aragão JA, Oliveira LAB. Ulcer dueto chronic venous disease: a sociodemographic study in Northeastern Brazil. Ann Vasc Surg. 2013; 27(5):571-6.

21. Freire MEM, Sawada NO, França ISX, Costa SFG, Oliveira CDB. Health-related quality of life among patients with advanced cancer: an integrative review. Rev Esc Enferm USP [Internet]. 2014 [cited 2016 Nov 26]; 48(2):351-61. Available from: http://www.scielo.br/pdf/ reeusp/v48n2/0080-6234-reeusp-48-02-357.pdf

22. Green J, Jester R, McKinley R, Pooler A. The impact of chronic venous leg ulcers: a systematic review. J Wound Care. 2014;23(12):601-12.

23. Kelechi TJ, Johnson JJ, Yates S. Chronic venous disease and venous leg ulcers: an evidence-based up date. J Vasc Nurs. 2015;33(2):36-46.

24. Malaquias SG, Bachion MM, Sant'Ana SMSC, Dallarmi CCB, Lino Junior RS, Ferreira OS. People with vascular ulcers in outpatient nursing care: a study of sociodemographic and clinical variables. Rev Esc Enferm USP [Internet]. 2012 [cited 2016 Dec 03];46(2):302-10. Available from: http://www.scielo.br/scielo.php?script=sci_arttext\&pid=S0080-62342012000200006\&lng=en\&nrm=iso\&tlng=en

25. Kouris A, Christodoulou C, Efstathiou V, Tsatovidou R, Torlidi-Kordera E, Zouridaki E, et al. Comparative study of quality of life and psychosocial characteristics in patients with psoriasis and leg ulcers. Wound Repair Regen. 2016;24(2):443-6.

26. Araújo DAL; Brito KKG; Santana EMF, Soares VL, Soares MJGO. Caracterização da qualidade de vida de pessoas com hanseníase em tratamento ambulatorial. Rev Pesqui Cuid. Fundam. 2016;8(4):5010-6.

27. Germano CMR, Bonato D, Maion VH, Silva de Avó LR, Melo DG, Fontanella BJB. New possible determinants of the quality of life of patients with treated thyroid cancer: a qualitative study. Cienc Saúde Coletiva. 2016;21(8):2451-62.

28. Bryant R, Nix NP. Acute and chronic wounds: current management concepts. Philadelphia: Elsevier Mosby; 2012.

29. Warriner III RA, Wilcox JR, Carter M, Stewart DG. More frequent visits to wound care clinics result in faster times to close diabetic foot and venous leg ulcers. Adv Skin Wound Care. 2012;25(11):494-501.

30. Tavakol M, Dennick R. Making sense of Cronbach's alpha. Int J Med Educ. 2011;27(2):53-55. 